\title{
Factors influencing asthma remission: a longitudinal study from childhood to middle age
}

\author{
John A Burgess, ${ }^{1}$ Melanie C Matheson, ${ }^{1}$ Lyle C Gurrin, ${ }^{1}$ Graham B Byrnes, ${ }^{2}$ \\ Kristie S Adams, ${ }^{1}$ Cathryn L Wharton, ${ }^{3}$ Graham G Giles, ${ }^{1,4}$ Mark A Jenkins, ${ }^{1}$ \\ John L Hopper, ${ }^{1}$ Michael J Abramson, ${ }^{5}$ E Haydn Walters, ${ }^{6}$ Shyamali C Dharmage ${ }^{1}$
}

${ }^{1}$ Centre for Molecular, Environmental, Genetic and Analytic Epidemiology, The University of Melbourne, Carlton, Victoria, Australia ${ }^{2}$ Biostatistics Group, International Agency for Research on Cancer, Lyon, France

${ }^{3}$ Victorian Cervical Cytology Registry, East Melbourne,

Victoria, Australia

${ }^{4}$ Cancer Epidemiology Centre, The Cancer Council Victoria, Carlton, Victoria, Australia ${ }^{5}$ Department of Epidemiology and Preventive Medicine, Monash University, The Alfred, Melbourne, Victoria, Australia ${ }^{6}$ Respiratory Research Group, Menzies Research Institute, The University of Tasmania, Hobart, Tasmania, Australia

\section{Correspondence to} John A Burgess, Centre for Molecular, Environmental, Genetic and Analytic Epidemiology, The University of Melbourne, Level 2, 723 Swanston Street, Carlton, Victoria 3053, Australia; jburgess@unimelb.edu.au

Received 15 July 2010 Accepted 24 February 2011 Published Online First 30 March 2011

\begin{abstract}
Objective To examine asthma remission from childhood to middle age.

Methods This was a population-based cohort study. In 1968 the Tasmanian Longitudinal Health Study enrolled 8583 7-year-old Tasmanian schoolchildren who were re-surveyed in 2004. Those reporting ever having asthma when last surveyed completed another questionnaire in 2007 ascertaining age at last asthma attack and asthma medication use. The main outcome measure was asthma remission, defined as no asthma attack for 2 years and no current asthma medication use, or no self-reported asthma in adult life but with parent-reported childhood asthma.
\end{abstract}

Results Of 5729 respondents to the 2004 survey, 1238 self-reported asthma. A further 573 denied asthma, but had parent-reported childhood asthma, giving a study sample of 1811. Asthma had remitted in 1177 (65.0\%) of whom 649 (55.1\%) were male. Childhood (OR 0.38, $95 \% \mathrm{Cl} 0.25$ to 0.58 ) and later-onset allergic rhinitis (0.42, 0.29 to 0.63$)$, childhood $(0.66,0.47$ to 0.94$)$ and later-onset eczema $(0.66,0.47$ to 0.92$)$, maternal asthma $(0.66,0.47$ to 0.92$)$ and childhood chronic bronchitis $(0.56,0.41$ to 0.76$)$ were negatively associated with remission. There was weaker evidence for a negative association between passive smoking $(0.75,0.54$ to 1.04$)$ and lower socio-economic status (p-trend 0.09) and remission. Childhood-onset asthma (3.76, 2.58 to 5.49) was more likely to remit than adult-onset asthma. Adult smoking was positively associated with remission in childhood-onset asthma $(1.49,1.06$ to 2.09). Sex did not influence remission. Conclusion While inherited factors cannot be changed, the effect of allergic rhinitis or eczema on asthma remission might be altered by early, aggressive treatment. Every effort should be made to lessen passive exposure to tobacco smoke.

\section{INTRODUCTION}

Establishing factors related to asthma remission could have clinical and public health implications. Few epidemiological studies have focused on asthma remission and most that have were crosssectional, ${ }^{1-3}$ while longitudinal studieshave been limited by short follow-up. ${ }^{4-6}$ Studies have also varied in their definition of remission, and these methodological limitations may have contributed to contrasting findings in published reports.

A community-based cohort study of children with wheeze by age 7 years found that $55 \%$ were in remission by age 21 years, ${ }^{7}$ but a later report ${ }^{8}$ stated that only $30 \%$ had remitted by age 42 years. A study of a large population-based cohort found that

\section{Key messages}

What is the key question?

What factors influence the remission of asthma from childhood to middle age?

What is the bottom line?

- Early, aggressive treatment of allergic rhinitis and eczema and reducing passive smoking exposure might facilitate asthma remission.

\section{Why read on?}

- This study, the world's largest and longestrunning population-based study of respiratory disease, uses data gathered prospectively over four decades to provide new evidence that these clinical and public health interventions might increase asthma remission.

$22 \%$ enjoyed a remission of asthma after an average 9-year follow-up, remission being more common for those aged $<20$ years and less common for those in middle age at study entry. ${ }^{6}$ Similarly, of 1153 adults aged 20-54 years from the Respiratory Health in Northern Europe study who reported ever asthma, 20\% experienced remission over an average 10-year follow-up. ${ }^{5}$ A more recent crosssectional study of 18873 Italian adults ${ }^{1}$ reported that for 1526 participants who self-reported asthma ever, $45.8 \%$ were in remission by age 44 years. Remission was more common for males (49.5\%) than females (41.6\%) and for those with childhoodonset $(60 \%)$ than adult-onset asthma $(15 \%)$. While the relationship between active $e^{9-13}$ and passive smoking ${ }^{14-17}$ and adult asthma has been well studied, less has been reported on these exposures and remission. ${ }^{45}$

Spanning childhood to middle age, the Tasmanian Longitudinal Health Study (TAHS) has followed a large population-based cohort for $>40$ years, prospectively gathering data on early life exposures and respiratory health. The TAHS provided an opportunity to examine trends and predictors of asthma remission with age. The study was approved by The University of Melbourne Human Research Ethics Committee.

\section{METHODS}

\section{Study population and data collection}

The TAHS began in 1968 when 8583 7-year-old Tasmanian school children were surveyed. Details of this and the subsequent survey in 1974 have been 
reported elsewhere. ${ }^{18} 19$ In 2004, some 7312 (85.2\%) of the original participants were traced ${ }^{20}$ and sent a detailed respiratory questionnaire. A completed questionnaire was provided by 5729 (78.4\%) of whom 1620 (28.3\%) reported asthma ever. Current addresses were found in mid-2007 for 1501 (92.7\%) who were sent a supplementary questionnaire ascertaining: (1) time since last asthma attack; (2) age at last asthma attack; and (3) asthma medication use in the previous 12 months. A completed questionnaire was received from 1267 (84.4\%) who formed the bulk of the sample for this analysis. The sample was supplemented by those 573 respondents to the 2004 survey who reported no asthma ever but who had parent-reported asthma at age 7 or 13 years. These subjects were regarded as having remitted asthma.

\section{Definitions}

Outcome

Asthma remission was defined by a participant reporting no attacks of asthma within the 2 years before completing the 2007 questionnaire together with no current asthma medication use, or by a participant reporting no history of asthma ever in the 2004 survey but with a parent report that the participant had asthma at age 7 or 13 years.

\section{Exposures}

Age at asthma onset was self-reported in the 2004 questionnaire. Participants' responses concerning 'asthma ever' and age at asthma onset were compared with their parents' responses to the same questions in 1968 and 1974. Where there was disagreement, the parents' responses were assumed to be correct. ${ }^{21}$

Smoking was self-reported in the 2004 questionnaire as 'ever smoking' or 'never smoking'.

Passive smoking was defined from the 2004 questionnaire as exposure to other peoples' tobacco smoke for at least $1 \mathrm{~h}$ daily.

Severe childhood asthma was defined from the 1968 questionnaire by the frequency or duration of asthma attacks. More than 10 attacks of asthma or an average attack duration of a week or more indicated severe asthma.

Bronchitis was defined from the 1968 questionnaire by an affirmative response to the question 'Has he/she at any time in his/her life suffered from attacks of bronchitis or attacks of cough with sputum (phlegm) in the chest?'

Childhood chronic bronchitis was defined as $>10$ attacks of bronchitis.

Parental smoking and parental asthma were self-reported in 1968.

Impaired lung function at age 7 years was defined as a forced expiratory volume in $1 \mathrm{~s}\left(\mathrm{FEV}_{1}\right)$ of $<80 \%$ of predicted. ${ }^{22}$

Childhood immunisation against diphtheria, pertussis and tetanus was ascertained from the child's school medical record. ${ }^{23}$

Body mass index at age 7 years was calculated from data recorded at the 1968 medical examination and classified as obese, overweight or normal. ${ }^{24}$

Infantile eczema was parent-reported in the 1968 questionnaire by an affirmative response to the question 'Did he/she have infantile (baby) eczema?'

Flexural eczema was parent-reported in the 1968 questionnaire by an affirmative response to the question 'Did he/she ever have eczema in the creases (bends) of elbows, wrists or knees?'

Childhood pneumonia, allergic rhinitis, doctor-diagnosed food/medicine allergy and urticaria were parent-reported in the 1968 questionnaire.

Socio-economic status at age 7 years was defined by the father's occupation and grouped into five categories according to the Australian Standard Classification of Occupations. ${ }^{25}$
Socio-economic status in 2004 was defined by the occupation of the participant and grouped into the same five categories.

\section{Analytical methods}

Age at asthma onset was grouped into three strata: (1) from birth to age 10 years; (2) between ages 10 and 20 years; and (3) after age 20 years. These strata enabled the explicit examination of variation in the association between the other exposures and asthma remission across different life stages. A logistic regression model examined the association between each exposure and asthma remission. Associations with a univariate $p$ value $\leq 0.15$ were included in a mutually adjusted multivariable logistic model. Adult smoking, passive smoking, sex and socio-economic status were retained in all models as confounders. Biologically plausible interaction terms were examined for inclusion in the model. Mutually adjusted multivariable logistic models were fitted separately to each age group to estimate the association between those same exposures and asthma remission within each age at asthma onset group. Estimates are presented as an OR with a $95 \%$ CI. A pooled estimate of the ORs across the life span to age 46 years was computed for each exposure using a meta-analysis of the results for each age group. The Cochran $\mathrm{Q}$ statistic tested homogeneity. Years of smoking prior to asthma diagnosis were compared using the Kruskal-Wallis test. Other categorical data were compared using the Pearson $\chi^{2}$ test. The analysis was performed using Stata statistical software, release 10.1. ${ }^{26}$

\section{RESULTS}

Of the 5729 respondents to the 2004 survey, 'asthma ever' was reported by 1620 (28.3\%), more commonly by females $(52.1 \%$, $\left.\chi_{1}^{2}, p=0.001\right)$. These 1620 were sent the supplementary questionnaire in 2007, and 1267 returned a completed questionnaire. Of those, 1238 provided sufficient information to enable classification as remitted or current asthma. Another 573 respondents to the 2004 survey who reported no asthma ever had parentreported asthma in the 1968 or 1974 survey and were added to the study sample which now numbered 1811, of whom 933 (51.5\%) were male. Of these 1811 participants, 1177 (65.0\%) were in remission. Of those in remission, $55.1 \%$ were male compared with $44.8 \%$ of those with current asthma $(p<0.0001)$. ORs with $95 \%$ CIs for the association between each exposure and asthma remission are shown in table 1.

Remission was more likely with childhood-onset than adultonset asthma and with a history of childhood pneumonia. Remission was less likely in females, in those whose mother had asthma, and those with impaired lung function at age 7 years, childhood chronic bronchitis, allergic rhinitis or eczema. Remission did not differ according to adult smoking, passive smoking, childhood exposure to parental smoking, food allergy, urticaria, severe childhood asthma, having at least one older sibling, exclusive breast feeding in the first 3 months of life, body mass index at age 7 years or childhood immunisation.

Table 2 shows the results from the mutually adjusted multivariable logistic model.

From the multivariable model, remission was less likely with maternal asthma, any eczema, any allergic rhinitis and childhood chronic bronchitis. Adult exposure to passive smoking was weakly associated with a decrease in the odds of remission, while there was a modest increase in the odds of remission with adult smoking. There was a non-significant downward trend in the odds of remission with lower socio-economic status. Age at which asthma began was inversely associated with remission. The odds of remission were 3.7-fold greater for childhood-onset 
Table 1 Univariate associations with asthma remission by the age of 46 years

\begin{tabular}{|c|c|c|c|}
\hline Characteristic or exposure (n) & Remitted, n (\%) & $\mathrm{OR}(95 \% \mathrm{Cl})$ & p Value \\
\hline \multicolumn{4}{|l|}{ Sex } \\
\hline Female (878) & $528(44.9)$ & $0.66(0.54$ to 0.80$)$ & $<0.001$ \\
\hline Male (933) & $649(55.1)$ & 1.00 & - \\
\hline \multicolumn{4}{|l|}{ Maternal asthma } \\
\hline Yes (301) & $179(59.5)$ & $0.74(0.57$ to 0.96$)$ & 0.021 \\
\hline No (1405) & $934(66.5)$ & 1.00 & - \\
\hline \multicolumn{4}{|l|}{ Paternal asthma } \\
\hline Yes (288) & $185(64.2)$ & 0.94 (0.72 to 1.22 ) & 0.633 \\
\hline No (1388) & $912(65.7)$ & 1.00 & - \\
\hline \multicolumn{4}{|l|}{ Maternal smoking } \\
\hline Yes (640) & $408(63.8)$ & 0.90 (0.73 to 1.10$)$ & 0.303 \\
\hline No (1071) & $709(66.2)$ & 1.00 & - \\
\hline \multicolumn{4}{|l|}{ Paternal smoking } \\
\hline Yes (988) & $640(64.8)$ & 0.93 (0.75 to 1.14 ) & 0.460 \\
\hline No (687) & $457(66.5)$ & 1.00 & - \\
\hline \multicolumn{4}{|l|}{ Allergic rhinitis } \\
\hline Childhood onset (400) & $256(64.0)$ & $0.45(0.33$ to 0.61$)$ & $<0.001$ \\
\hline Later onset (853) & $497(58.3)$ & $0.35(0.27$ to 0.46$)$ & $<0.001$ \\
\hline None (495) & $395(79.8)$ & 1.00 & - \\
\hline \multicolumn{4}{|l|}{ Eczema } \\
\hline Childhood onset (381) & $233(61.2)$ & 0.65 (0.50 to 0.83$)$ & 0.001 \\
\hline Later onset (582) & $343(58.9)$ & 0.59 (0.47 to 0.74$)$ & $<0.001$ \\
\hline None (848) & $601(70.9)$ & 1.00 & - \\
\hline \multicolumn{4}{|l|}{ Food allergy } \\
\hline Yes (187) & $116(62.0)$ & $0.84(0.62$ to 1.15$)$ & 0.289 \\
\hline No (1582) & $1043(66.0)$ & 1.00 & - \\
\hline \multicolumn{4}{|l|}{ Urticaria } \\
\hline Yes (427) & $280(65.6)$ & 1.01 (0.80 to 1.27$)$ & 0.949 \\
\hline No (1321) & $864(65.4)$ & 1.00 & - \\
\hline \multicolumn{4}{|l|}{ Childhood chronic bronchitis } \\
\hline Yes (328) & $206(62.8)$ & 0.68 (0.52 to 0.89$)$ & 0.005 \\
\hline No (873) & $622(71.3)$ & 1.00 & - \\
\hline \multicolumn{4}{|l|}{ Severe childhood asthma } \\
\hline Yes (376) & $254(67.6)$ & 1.15 (0.91 to 1.47 ) & 0.249 \\
\hline No (1434) & $923(64.4)$ & 1.00 & - \\
\hline \multicolumn{4}{|l|}{ Exclusive breast feeding } \\
\hline Yes (703) & $462(65.7)$ & $1.02(0.84$ to 1.25$)$ & 0.812 \\
\hline No (1068) & $696(65.2)$ & 1.00 & - \\
\hline \multicolumn{4}{|l|}{ At least one older sibling } \\
\hline Yes (1180) & $779(66.0)$ & 1.14 (0.93 to 1.39$)$ & 0.211 \\
\hline No (631) & $398(63.1)$ & 1.00 & - \\
\hline \multicolumn{4}{|l|}{ Childhood pneumonia } \\
\hline Yes (376) & $265(70.5)$ & $1.34(1.04$ to 1.71$)$ & 0.021 \\
\hline No (1387) & $889(64.1)$ & 1.00 & - \\
\hline \multicolumn{4}{|l|}{ Childhood immunisation (DPT) } \\
\hline Yes (1512) & $971(64.2)$ & 0.85 (0.58 to 1.24$)$ & 0.394 \\
\hline No (131) & $89(67.9)$ & 1.00 & \\
\hline \multicolumn{4}{|c|}{ Impaired lung function (at age 7 years) } \\
\hline Yes (72) & $38(52.8)$ & $0.59(0.37$ to 0.94$)$ & 0.028 \\
\hline No (1739) & $1139(65.5)$ & 1.00 & - \\
\hline Body mass index (at age 7 year & & & \\
\hline Obese (9) & $5(55.6)$ & 0.66 (0.18 to 2.48$)$ & 0.540 \\
\hline Overweight (100) & $66(66.0)$ & 1.03 (0.67 to 1.58 ) & 0.897 \\
\hline Normal (1585) & $1036(65.4)$ & 1.00 & - \\
\hline Life stage at asthma onset & & & \\
\hline Childhood (1192) & $880(73.8)$ & 3.28 (2.62 to 4.10$)$ & $<0.001$ \\
\hline Adolescence (148) & $75(50.7)$ & 1.19 (0.82 to 1.73$)$ & 0.351 \\
\hline Adult (456) & $211(46.3)$ & 1.00 & - \\
\hline Adult smoking & & & \\
\hline Ever smoking (1096) & $716(65.3)$ & 1.04 (0.85 to 1.26$)$ & 0.718 \\
\hline Never smoking (707) & $456(64.5)$ & 1.00 & - \\
\hline
\end{tabular}

Table 1 Continued

\begin{tabular}{|c|c|c|c|}
\hline Characteristic or exposure (n) & Remitted, n (\%) & OR $(95 \%$ CI) & p Value \\
\hline \multicolumn{4}{|l|}{ Passive adult smoking } \\
\hline Yes (501) & $316(63.1)$ & 0.89 (0.72 to 1.11$)$ & 0.306 \\
\hline No (1278) & $839(65.7)$ & 1.00 & - \\
\hline \multicolumn{4}{|l|}{ Childhood socio-economic status } \\
\hline Level 1 (369) & $244(66.1)$ & 1.00 & - \\
\hline Level 2 (108) & $69(63.9)$ & 0.91 (0.58 to 1.42 ) & 0.667 \\
\hline Level 3 (520) & $337(64.8)$ & $0.94(0.71$ to 1.25$)$ & 0.684 \\
\hline Level 4 (473) & $319(67.4)$ & $1.06(0.79$ to 1.42$)$ & 0.687 \\
\hline Level 5 (229) & $136(59.4)$ & $0.75(0.53$ to 1.05$)$ & 0.097 \\
\hline \multicolumn{4}{|l|}{ Adult socio-economic status } \\
\hline Level 1 (515) & $338(65.6)$ & 1.00 & - \\
\hline Level 2 (202) & $131(64.9)$ & 0.97 (0.69 to 1.36$)$ & 0.988 \\
\hline Level 3 (325) & $230(70.8)$ & $1.27(0.94$ to 1.71$)$ & 0.338 \\
\hline Level 4 (343) & $216(63.0)$ & 0.89 (0.67 to 1.18$)$ & 0.425 \\
\hline Level 5 (403) & $251(62.3)$ & 0.86 (0.66 to 1.13 ) & 0.294 \\
\hline
\end{tabular}

asthma and 1.3-fold greater for adolescent-onset asthma compared with adult-onset asthma. In the multivariable model, sex did not influence remission. Further examination found that the effect of sex was confounded by life stage at asthma onset.

A parsimonious model derived from the multivariable model omitted childhood pneumonia and impaired lung function, but made no substantive change to the estimates (results not presented). However, the downward trend in socio-economic status became a little more significant ( $p$-trend 0.09).

The predicted probability of remission for those with childhood-onset asthma was $76 \%$ (95\% CI $73 \%$ to $79 \%$ ), adolescentonset asthma $54 \%$ (42\% to $66 \%$ ) and adult-onset asthma $49 \%$ ( $41 \%$ to $57 \%$ ). Age at asthma onset modelled as a continuous variable was associated with a $5.0 \%$ decrease in the odds of remission (OR 0.95, 95\% CI 0.94 to 0.96 ; $p<0.001$ ) for each year increase in age at asthma onset. Overall, those in remission had an earlier mean age at asthma onset than those with current asthma (9.2 years vs 16.5 years; $p<0.001)$. Males in remission had an earlier age at asthma onset than females ( 7.0 years vs 12.1 years; $\mathrm{p}<0.001)$. For current asthma, males also had an earlier age at asthma onset than females (13.1 years vs 19.3 years; $p<0.001$ ).

The effect of age at asthma onset on remission was examined by fitting mutually adjusted logistic models to each of the life stages when asthma began (table 3 ).

For those with childhood-onset asthma, remission was less likely for those whose mother had asthma, those with any eczema or allergic rhinitis and those with childhood chronic bronchitis. Remission was modestly less likely for those exposed to adult passive smoking. However, remission was more likely for adult smokers. Comparing those with remitted asthma with those with current asthma in this childhood-onset group, no difference was found in the mean age at which smoking started (16.17 and 16.47 years, respectively; $\mathrm{p}=0.398$ ) or stopped $(29.84$ and 29.35 years, respectively; $p=0.614$ ).

For those with adolescent-onset asthma, remission was less likely with any allergic rhinitis, while for those with adult-onset asthma, remission was less likely with allergic rhinitis that began after childhood. Adult smoking did not influence remission in either of these age at asthma onset groups. However, among those with adolescent-onset asthma, those who did not remit were smoking for 2.72 years longer before asthma started than those who did remit $(p=0.006)$, while among those with adult-onset asthma the equivalent figure was 2.35 years $(\mathrm{p}=0.011)$. 
Table 2 Mutually adjusted multivariable model examining associations with asthma remission by the age of 46 years*

\begin{tabular}{|c|c|c|}
\hline Characteristic or exposure & OR $(95 \% \mathrm{Cl})$ & p Value \\
\hline \multicolumn{3}{|l|}{ Sex } \\
\hline Female & $0.84(0.62$ to 1.12$)$ & 0.235 \\
\hline Male & 1.00 & - \\
\hline Maternal asthma & $0.64(0.46$ to 0.90$)$ & 0.009 \\
\hline \multicolumn{3}{|l|}{ Eczema } \\
\hline Childhood onset & 0.68 (0.46 to 0.96$)$ & 0.030 \\
\hline Later life onset & $0.66(0.47$ to 0.91$)$ & 0.012 \\
\hline None & 1.00 & - \\
\hline \multicolumn{3}{|l|}{ Allergic rhinitis } \\
\hline Childhood onset & $0.38(0.25$ to 0.58$)$ & $<0.001$ \\
\hline Later life onset & $0.42(0.29$ to 0.63$)$ & $<0.001$ \\
\hline None & 1.00 & - \\
\hline Childhood pneumonia & $0.96(0.70$ to 1.320$)$ & 0.789 \\
\hline Childhood chronic bronchitis & $0.56(0.40$ to 0.77$)$ & $<0.001$ \\
\hline Impaired lung function (at age 7 years) & $0.80(0.42$ to 1.53$)$ & 0.503 \\
\hline \multicolumn{3}{|l|}{ Life stage at asthma onset } \\
\hline Childhood & $3.69(2.52$ to 5.40$)$ & $<0.001$ \\
\hline Adolescence & $1.30(0.72$ to 2.32$)$ & 0.382 \\
\hline Adult & 1.00 & - \\
\hline \multicolumn{3}{|l|}{ Adult smoking } \\
\hline Ever smoking & $1.31(0.98$ to 1.75$)$ & 0.070 \\
\hline Never smoking & 1.00 & - \\
\hline \multicolumn{3}{|l|}{ Passive adult smoking } \\
\hline Yes & $0.77(0.55$ to 1.07$)$ & 0.121 \\
\hline No & 1.00 & - \\
\hline \multicolumn{3}{|l|}{ Adult socio-economic status } \\
\hline Level 1 (highest) & 1.00 & - \\
\hline Level 2 & $1.00(0.60$ to 1.67$)$ & 0.988 \\
\hline Level 3 & $0.92(0.60$ to 1.41$)$ & 0.698 \\
\hline Level 4 & $0.84(0.56$ to 1.27$)$ & 0.411 \\
\hline Level 5 (lowest) & 0.73 (0.49 to 1.08$)$ & $\begin{array}{l}0.114 \\
p \text {-trend } 0.104\end{array}$ \\
\hline
\end{tabular}

Significant results are shown in bold.

*The model contains variables from table 1 with a $p$ value $\leq 0.15$.

The pooled estimates were similar to those from the mutually adjusted logistic model, reflecting homogeneity across the age at asthma onset groups.

\section{DISCUSSION}

Using the TAHS, one of the world's largest and longest-running studies of respiratory disease, we found that asthma remission by middle age was less likely for those with allergic rhinitis or eczema, with childhood chronic bronchitis or a history of maternal asthma. However, remission was more likely for those whose asthma began before the age of 10 years compared with those with adult-onset asthma and for those adult smokers whose asthma began before the age of 10 years. Exposure to passive smoking and lower strata of socio-economic status were modestly associated with a lesser likelihood of remission. Sex was not independently associated with remission.

A major strength of our study is that it draws on longitudinal data gathered over 40 years, allowing validation of responses provided by adult participants. Our remitted cohort included adults who had forgotten childhood asthma. In earlier crosssectional studies examining asthma remission, similar individuals would have been omitted, suggesting that our study could identify prognostic factors for remission more accurately. Further strengths are the size of our cohort and relatively small loss to follow-up.

Allergic rhinitis and eczema had strong negative effects on asthma remission, irrespective of age at asthma onset. A previous study found a negative association between allergic rhinitis and remission over a 10-year follow-up ${ }^{27}$ but our findings on the negative relationship between both allergic rhinitis and eczema and asthma remission over a near 40-year follow-up are novel. Previously, we examined the effect of both allergic rhinitis and eczema on asthma incidence after childhood and persistence from childhood. Allergic rhinitis was independently associated with both incidence and persistence. Eczema was independently associated with incidence, its association with persistence being confounded by allergic rhinitis. ${ }^{28} 29$ The apparent contradiction between these earlier results for eczema and those from the current study is likely to be due to the stricter definition of remission in the current study, resulting in different study samples.

Together with their negative effects on asthma remission from the current study, our earlier findings highlight the dual effect of allergic rhinitis and eczema on the natural history of asthma. They strengthen the case for trials of more aggressive intervention for allergic rhinitis or eczema, aimed at preventing asthma or modifying its clinical course. ${ }^{30} 31$

Age at asthma onset strongly predicted remission, which became less likely as age at asthma onset increased. Remission was 3.7 times as likely with childhood-onset asthma and $>1.3$ times as likely with adolescent-onset asthma compared with adult-onset asthma. These findings were consistent with de Marco et $a l^{1}$ who also found remission more likely with childhood-onset asthma. It is well established that childhood is the life stage that carries the greatest risk for asthma development. Our findings add weight to the importance of early-life events in the natural history of asthma and suggest that the prognosis of childhood-onset asthma is not necessarily unfavourable, important information for the parents of a child with asthma.

The evidence is strong that genetic factors influence asthma onset, but their influence on asthma remission has been less well studied. Our results suggest that inherited maternal factors are the more important. While the negative influence of maternal asthma was strongest in childhood-onset asthma, it was consistently negative in adolescent- and adult-onset asthma, suggesting that the influence of maternal asthma on remission was important up to middle age. This again supports de Marco et al who found that a family history of asthma was associated with a lesser chance of remission throughout life. ${ }^{2}$

Respiratory infection has been strongly associated with incident asthma, while greater exposure to other infectious agents has been found to be protective. However, the role of respiratory infection in asthma remission is unclear. We found that childhood chronic bronchitis was negatively associated with remission in childhood-onset asthma. This contrasted with our finding for childhood pneumonia, suggesting that continuing or repeated respiratory inflammation rather than a single episode had the stronger influence on prospects for remission.

We found a complex relationship between smoking and remission. For those with adolescent- or adult-onset asthma, adult smoking appeared not to influence remission. However, in each age group, years of personal smoking prior to the onset of asthma were significantly greater in those who did not remit than in those who did, suggesting that a longer duration of smoking prior to asthma onset might affect prospects for remission unfavourably. In contrast, for those with childhoodonset asthma we found a direct association between smoking and remission, similar to Vonk et al. ${ }^{32}$ This finding might be linked to the 'healthy smoker' effect where those who take up smoking have better lung function than those who do not. ${ }^{33}$ An extension of this is that among those with childhood-onset 
Table 3 Mutually adjusted models for asthma remission with different life stages at asthma onset*

\begin{tabular}{|c|c|c|c|c|c|}
\hline \multirow[b]{2}{*}{ Remitted asthma: n (\%) } & \multicolumn{3}{|l|}{ Life stage at asthma onset } & \multirow[b]{2}{*}{$\begin{array}{l}\text { Homogeneity } \\
\text { test p value }\end{array}$} & \multirow[b]{2}{*}{$\neq$ Pooled OR $(95 \% \mathrm{Cl})$} \\
\hline & $\begin{array}{l}\text { Childhood onset }+(\mathrm{n}=1192) \\
880(73.8) \\
\text { OR }(95 \% \mathrm{Cl})\end{array}$ & $\begin{array}{l}\text { Adolescent onset }+(\mathrm{n}=148) \\
75(50.7) \\
\text { OR }(95 \% \text { CI })\end{array}$ & $\begin{array}{l}\text { Adult onset }+(n=456) \\
211(46.3) \\
\text { OR }(95 \% \text { CI })\end{array}$ & & \\
\hline Female & 0.75 (0.53 to 1.06$)$ & $2.06(0.59$ to 7.22$)$ & 1.18 (0.53 to 2.59$)$ & 0.215 & 0.85 (0.63 to 1.15$)$ \\
\hline Male & 1.00 & 1.00 & 1.00 & & \\
\hline Maternal asthma & $0.64(0.44$ to 0.93$)$ & $0.38(0.07$ to 2.03$)$ & $0.90(0.37$ to 2.24$)$ & 0.638 & $0.66(0.47$ to 0.93$)$ \\
\hline Later life onset & $0.57(0.38$ to 0.84$)$ & $0.82(0.21$ to 3.11$)$ & $1.00(0.46$ to 2.16$)$ & 0.410 & $0.65(0.46$ to 0.91$)$ \\
\hline Never & 1.00 & 1.00 & 1.00 & - & - \\
\hline \multicolumn{6}{|l|}{ Allergic rhinitis } \\
\hline Childhood onset & $0.38(0.23$ to 0.61$)$ & $0.07(0.01$ to 0.69$)$ & $0.59(0.20$ to 1.76$)$ & 0.258 & $0.38(0.25$ to 0.59$)$ \\
\hline Later life onset & $0.45(0.28$ to 0.73$)$ & $0.09(0.01$ to 0.71$)$ & $0.43(0.19$ to 0.98$)$ & 0.329 & $0.42(0.28$ to 0.63$)$ \\
\hline Never & 1.00 & 1.00 & 1.00 & - & - \\
\hline Level 1 (highest) & 1.00 & 1.00 & 1.00 & - & - \\
\hline Level 2 & 0.98 (0.53 to 1.78 ) & 0.21 (0.03 to 1.42 ) & 2.27 (0.58 to 8.90$)$ & 0.141 & 0.99 (0.58 to 1.68$)$ \\
\hline Level 3 & 0.97 (0.60 to 1.58 ) & $0.76(0.12$ to 4.92$)$ & 0.78 (0.27 to 2.28$)$ & 0.915 & 0.93 (0.60 to 1.42 ) \\
\hline Level 4 & $0.96(0.59$ to 1.55$)$ & $0.36(0.07$ to 1.73$)$ & 0.43 (0.15 to 1.22$)$ & 0.234 & $0.79(0.52$ to 1.20$)$ \\
\hline Level 5 (lowest) & 0.93 (0.58 to 1.48 ) & $0.29(0.06$ to 1.42$)$ & 0.30 (0.12 to 0.78$)$ & 0.061 & $0.70(0.47$ to 1.05$)$ \\
\hline
\end{tabular}

Significant results $(p<0.05)$ are shown in bold.

*The exposures used in these models were those from the parsimonious multivariable model.

†Number represents those with data on both life stage and asthma remission.

†Fixed effect estimate.

asthma, those who begin smoking may have better lung function and less severe disease than those who do not, and having self-selected, might be more likely to remit. Alternatively, starting smoking in those who had childhood-onset asthma might reflect remission - that is, reverse causation might explain this association.

Exposure to passive smoking was modestly associated with a reduced likelihood of remission in childhood-onset asthma and across the span to middle age. Perhaps the lack of choice of the individual with asthma in passive smoking exposure was important in the clinical course of the disease.

Lower socio-economic status negatively influenced asthma remission, perhaps reflecting less health consciousness or less access to effective treatment, issues that could be modified by improving asthma education and making preventive medication more affordable.

Finally, sex was not independently associated with remission, a finding in agreement with de Marco et al. ${ }^{1}$ However. Sekerel et $a l^{34}$ found that in a paediatric cohort, female sex independently predicted lesser likelihood of remission to late adolescence. It is possible that the latter finding was related to more limited follow-up than in our study and it is notable that females tend to develop asthma in adult life, the life stage where we found asthma was least likely to remit. The likely explanation for our finding is that the negative association between female sex and remission was confounded by life stage at asthma onset.

An important limitation of our study is reliance on parental recall of their child's asthma. A further limitation lies with our definition of remission, more accurately 'clinical remission'. Earlier studies have identified continuing bronchial hyperresponsiveness in clinically remitted asthma ${ }^{32}$ and the potential for clinically remitted asthma to relapse with further followup. ${ }^{35}$ Consequently, complete physiological remission, marked by the presence of normal lung function, absence of bronchial hyper-responsiveness and absence of symptoms, is the preferred definition. However, our data did not allow this as the study end point. In addition, our definition of remission cannot encompass subjects who developed asthma after the 1974 survey, experienced remission promptly and then did not remember their asthma when adults. Finally, we acknowledge that small numbers, particularly for adolescent-onset asthma in table 3 , should prompt caution in interpreting the results.

In summary, we have identified both environmental and familial factors associated with asthma remission. While genetic factors are not modifiable, intervention trials with aggressive treatment of allergic rhinitis and eczema would be worthwhile, and discouraging passive smoking is an important public health issue.

Funding The Tasmanian Longitudinal Health Study is supported by grants from the National Health and Medical Research Council (NHMRC) of Australia, the Victorian and Tasmanian Asthma Foundations, the Clifford Craig Medical Research Trust and the Royal Hobart Hospital Research Foundation. MCM, JLH, LCG and SCD are supported by the NHMRC.

Competing interests None.

Ethics approval This study was conducted with the approval of the Human Research Ethics Committee, The University of Melbourne.

Contributors The analysis and interpretation of data was led by $J A B$ with support from LCG, GBB and SCD. Initial drafting of the manuscript was performed by JAB with critical revision of the manuscript for important intellectual content by all authors. JAB is the guarantor. JAB, LCG, GBB and SCD had full access to the data (including statistical reports and tables) in the study. JAB takes responsibility for the integrity of the data and the accuracy of the data analysis.

Provenance and peer review Not commissioned; externally peer reviewed.

\section{REFERENCES}

1. De Marco R, Locatelli F, Cerveri l, et al. Incidence and remission of asthma: a retrospective study on the natural history of asthma in Italy. J Allergy Clin Immunol 2002;110:228-35. 
2. de Marco R, Pattaro C, Locatelli F, et al. Influence of early life exposures on incidence and remission of asthma throughout life. J Allergy Clin Immunol 2004;113:845-52.

3. Plaschke PP, Janson C, Norrman E, et al. Onset and remission of allergic rhinitis and asthma and the relationship with atopic sensitization and smoking. Am J Respir Crit Care Med 2000:162:920-4.

4. Ronmark $\mathbf{E}$, Jonsson $\mathbf{E}$, Lundback B. Remission of asthma in the middle aged and elderly: report from the Obstructive Lung Disease in Northern Sweden study. Thorax 1999:54:611-13.

5. Holm M, Omenaas E, Gislason T, et al. Remission of asthma: a prospective longitudinal study from northern Europe (RHINE study). Eur Respir J 2007;30:62-5.

6. Bronnimann S, Burrows B. A prospective study of the natural history of asthma. Remission and relapse rates. Chest 1986;90:480-4.

7. Martin AJ, McLennan LA, Landau LI, et al. The natural history of childhood asthma to adult life. Br Med J 1980;280:1397-400.

8. Phelan PD, Robertson CF, Olinsky A. The Melbourne asthma study: 1964-1999. J Allergy Clin Immunol 2002:109:189-94.

9. Avila L, Soto-Martinez ME, Soto-Quiros ME, et al. Asthma, current wheezing, and tobacco use among adolescents and young adults in Costa Rica. J Asthma 2005:42:543-7.

10. Gilliland FD, Islam T, Berhane $\mathrm{K}$, et al. Regular smoking and asthma incidence in adolescents. Am J Respir Crit Care Med 2006;174:1094-100.

11. Gomez M, Vollmer WM, Caceres ME, et al. Adolescent smokers are at greater risk for current asthma and rhinitis. Int J Tuberc Lung Dis 2009;13:1023-8.

12. Gwynn RC. Risk factors for asthma in US adults: results from the 2000 Behavioral Risk Factor Surveillance System. J Asthma 2004;41:91-8.

13. Jamrozik E, Knuiman MW, James A, et al. Risk factors for adult-onset asthma: a 14-year longitudinal study. Respirology 2009:14:814-21.

14. Eisner MD. Passive smoking and adult asthma. Immunol Allergy Clin North Am 2008;28:521-37.

15. Flodin $\mathbf{U}$, Jonsson $\mathrm{P}$, Ziegler $\mathrm{J}$, et al. An epidemiologic study of bronchial asthma and smoking. Epidemiology 1995;6:503-5.

16. Jaakkola MS, Piipari R, Jaakkola N, et al. Environmental tobacco smoke and adult-onset asthma: a population-based incident case-control study. Am J Public Health 2003;93:2055-60.

17. Weiss ST, Utell MJ, Samet JM. Environmental tobacco smoke exposure and asthma in adults. Environ Health Perspect 1999;107(Suppl 6):891-5.

18. Gibson HB, Silverstone H, Gandevia B, et al. Respiratory disorders in seven-year-old children in Tasmania. Aims, methods and administration of the survey. Med J Aust 1969;2:201-5

19. Giles GG, Lickiss N, Gibson HB, et al. Respiratory symptoms in Tasmanian adolescents: a follow up of the 1961 birth cohort. Aust N Z J Med 1984;14:631-7.
20. Wharton C, Dharmage S, Jenkins $\mathrm{M}$, et al. Tracing 8,600 participants 36 years afte recruitment at age seven for the Tasmanian Asthma Study. Aust N Z J Public Health 2006;30:105-10.

21. Burgess JA, Walters EH, Byrnes GB, et al. Who remembers whether they had asthma as children? J Asthma 2006;43:727-30.

22. Zapletal A, Paul T, Samanek M. [Significance of contemporary methods of lung function testing for the detection of airway obstruction in children and adolescents (author's transl)]. Z Erkr Atmungsorgane 1977;149:343-71.

23. Nakajima K, Dharmage SC, Carlin JB, et al. Is childhood immunisation associated with atopic disease from age 7 to 32 years?. Thorax 2007;62:270-5.

24. Cole TJ, Bellizzi MC, Flegal KM, et al. Establishing a standard definition for child overweight and obesity worldwide: international survey. BMJ 2000;320:1240-3.

25. Australian Bureau of Statistics. Australian Standard Classification of Occupations 1997. Cat. No: 1220.0. 2nd edn. Canberra: Australian Bureau of Statistics (ABS), 1997.

26. StataCorp. Stata Statistical Software:Release 10.1. College Station (TX): Stata Corporation.

27. Ekerljung L, Ronmark E, Larsson $\mathrm{K}$, et al. No further increase of incidence of asthma: incidence, remission and relapse of adult asthma in Sweden. Respir Med 2008;102:1730-6.

28. Burgess JA, Dharmage SC, Byrnes GB, et al. Childhood eczema and asthma incidence and persistence: a cohort study from childhood to middle age. J Allergy Clin Immunol 2008;122:280-5.

29. Burgess JA, Walters EH, Byrnes GB, et al. Childhood allergic rhinitis predicts asthma incidence and persistence to middle age: a longitudinal study. J Allergy Clin Immunol 2007;120:863-9.

30. Bousquet J, Khaltaev N, Cruz AA, et al. Allergic Rhinitis and its Impact on Asthma (ARIA) 2008 update (in collaboration with the World Health Organization, GA(2)LEN and AllerGen). Allergy 2008;63(Suppl 86):8-160.

31. Darsow U, Wollenberg A, Simon D, et al. ETFAD/EADV eczema task force 2009 position paper on diagnosis and treatment of atopic dermatitis. J Eur Acad Dermatol Venereol 2010;24:317-28.

32. Vonk JM, Postma DS, Boezen HM, et al. Childhood factors associated with asthma remission after 30 year follow up. Thorax 2004;59:925-9.

33. Becklake MR, Lalloo U. The 'healthy smoker': a phenomenon of health selection? Respiration 1990;57:137-44.

34. Sekerel BE, Civelek E, Karabulut E, et al. Are risk factors of childhood asthma predicting disease persistence in early adulthood different in the developing world? Allergy 2006;61:869-77.

35. Taylor DR, Cowan J0, Greene JM, et al. Asthma in remission: can relapse in early adulthood be predicted at 18 years of age? Chest 2005;127:845-50.

\section{Thorax Online Archive}

Visit our Online Archive - available back to 1946. Subscribers may access the entire archive freely. Non-subscribers have free access to all articles prior to 2006. A simple one-time registration is required that grants access to all the free archive content, across all of our specialist titles. To view or to register visit thorax.bmj.com. 